\title{
PREVALENCE OF DYSLIPIDAEMIA AMONG DOCTORS AND PARAMEDICAL STAFF- SINGLE CENTER STUDY
}

\author{
Deepesh Agrawal', Ramanand Prasad Sinha², Rajat Bohra ${ }^{3}$
}

${ }_{1}^{1}$ Associate Professor, Department of Cardiology, Mahatma Gandhi Medical University, Sitapura, Jaipur, Rajasthan, India.

${ }^{2}$ Associate Professor, Department of Cardiology, Mahatma Gandhi Medical University, Sitapura, Jaipur, Rajasthan, India.

${ }^{3}$ Associate Professor, Department of Preventive Medicine, Mahatma Gandhi Medical University, Sitapura, Jaipur, Rajasthan, India.

ABSTRACT

\section{BACKGROUND}

Dyslipidaemia is very common risk factor for future cardiac events. We doctors and staff, always involve in various trials related to dyslipidaemia but remain unaware of the prevalence among us. Dyslipidaemia is now a days very prevalent among various population, due various life style related factors, significant risk for future atherothrombotic cardiovascular events and has important correlation with the working environment. The aim of this study was to determine the prevalence of dyslipidaemia among doctors and paramedical staff in our medical university as working environment in our hospital is very stressful.

\section{MATERIALS AND METHODS}

It was a single center cross sectional study. We recruited total 700 medical professions (220 doctors and 480 para medical staff). Detailed laboratory examination was done. Data was collected in Performa having questionnaires about physical activity, job stress, sleeping hours, working hours, alcoholism and smoking habits. Correlation with multistep regression analysis and coefficient of contingency were derived from the results.

\section{RESULTS}

Prevalence of increased total cholesterol, LDL cholesterol, triglycerides and decrease HDL was in $48.90 \%, 32.73 \%$ and $36.82 \%$.and $68.18 \%$ among doctors and $39.58 \%, 39.59 \%, 40.42 \%$ and $58.33 \%$ among paramedical staff.

\section{CONCLUSION}

Our study has shown that due to increased job stress and other related factors among doctors and staff, decreased HDL and increased total cholesterol was found among doctors and paramedical staff. Females are more dyslipidemic versus males and dyslipidaemia increased with age. The prevalence of Dyslipidaemia was much more than the general population. This was due to effects of differences in life-style and behaviour such as physical inactivity, job stress, work load, altered sleep pattern, alcoholic consumption etc. in the general population.

\section{KEY WORDS}

Dyslipidaemia, Paramedical Staff.

HOW TO CITE THIS ARTICLE: Agrawal D, Sinha RP, Bohra R. Prevalence of dyslipidaemia among doctors and paramedical staffsingle center study. J. Evolution Med. Dent. Sci. 2018;7(43):4648-4650, DOI: 10.14260/jemds/2018/1037

\section{BACKGROUND}

Cardiovascular disease (CVD) is the leading cause of death worldwide, and mortality due to CVD is higher in low and middle income countries.1,2 In India, there has been an alarming increase in the prevalence of CVD over the three decades so much so that it accounts for $24 \%$ of all deaths among adults aged 25-69 years. ${ }^{3}$ Asian Indians have been found to develop CVD at an younger age than other populations, 4 the likely causes for the increase in the CVD rates include lifestyle changes associated with urbanization and the epidemiologic and nutritional transitions that accompany economic development. ${ }^{5}$ Dyslipidaemia has been closely linked to CVD and is a key independent modifiable

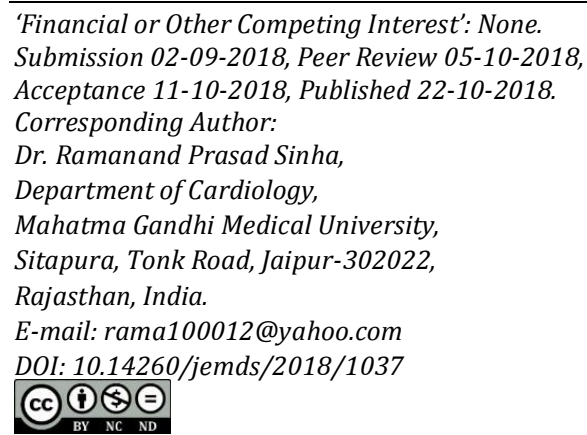

Little information exists on prevalence of dyslipidaemia in India and especially in professional workers. The working population represents a large proportion of the general population. Employees spend most of the time of their life in their working place. Hospitals are an ideal environment to collect and disseminate information on quality of life and cardiovascular risk factors. Hospital workers are influenced by their work environment; lots of stress that's led to change in life style. In health care services, the value of determination of dyslipidaemia derives largely from its potential to reduce the risk of cardiovascular disease. So, we planned to study the prevalence of dyslipidaemia in among doctors and paramedical staff in Mahatma Gandhi Medical University, Jaipur.

\section{MATERIALS AND METHODS}

This was a cross sectional epidemiological study investigating prevalence of dyslipidaemia among doctors and staff working in Mahatma Gandhi Medical University and Hospital, Jaipur. All the doctors and paramedical staff were included in the 
study. Out of 232 doctors working in the hospital, 12 didn't give their consent while out of 780 staff members, 300 didn't give their consent. Thus, 220 doctors and 480 paramedical staff members who participated in the study, were examined in Department of General Medicine and Department of Cardiology. All participants were more than 28 years of age. Data was collected on a specially designed Performa having multiple questionnaires describing baseline demographic profile, personal habits and physical exercise (IPAQ Protocol) ${ }^{8}$ job stress 9 , work load and sleep pattern. Participants underwent detailed physical and laboratory testing. Laboratory measurement were done after at least 12 hours of fasting. Venous blood sample was collected to estimate lipid profile levels and finally analysed by standard enzymatic methods. Various enzymes were used for estimation total cholesterol, total triglyceride and level of LDL and HDL.

\section{Statistical Analyses}

Analyses were completed using SUDANN (version 8.0) to take into account sample weights and design effects. The data was analysed and expressed in number and percentages. For quantitative data, mean and standard deviation (SD) were calculated.

\section{RESULTS}

In our study, mean age in doctors was $43.66 \pm 23.86$ and in paramedical staff $46.48 \pm 21.84$. Triglyceride $168.62 \pm 36.14$ in doctors versus $158.43 \pm 24.7$ in paramedical staff, HDL $42.16 \pm$ 32.14 in doctors versus $41.43 \pm 23.2$ in paramedical staff; total cholesterol $206.35 \pm 23.14$ in doctors versus $198.13 \pm 22.13$ in paramedical staff; LDL cholesterol level $136.12 \pm 18.14$ in doctors versus $143.12 \pm 18.14$ in paramedical staff (table 1 ).

\begin{tabular}{|c|c|c|}
\hline Variables (Unit) & Doctors (Mean SD) & Staff (Mean SD) \\
\hline Age (years) & $43.66 \pm 23.86$ & $46.48 \pm 21.84$ \\
\hline TG $(\mathrm{mg} / \mathrm{dl})$ & $168.62 \pm 36.14$ & $158.43 \pm 24.7$ \\
\hline $\mathrm{HDL}(\mathrm{mg} / \mathrm{dl})$ & $42.16 \pm 32.14$ & $41.43 \pm 23.2$ \\
\hline $\mathrm{TC}(\mathrm{mg} / \mathrm{dl})$ & $206.35 \pm 23.14$ & $198.13 \pm 22.13$ \\
\hline $\mathrm{LDL}(\mathrm{mg} / \mathrm{dl})$ & $136.12 \pm 18.14$ & $143.12 \pm 18.14$ \\
\hline Table 1. Demographic Profile of the Study Population \\
\hline
\end{tabular}

For total cholesterol levels, 90 doctors out of 220 had increased total cholesterol and prevalence is $40.90 \% .190$ paramedical staff out of 480 had increased total cholesterol and prevalence is $39.58 \%$.

For LDL cholesterol level, 72 doctors out of 220 had increased LDL and prevalence in $32.73 \% .190$ paramedical staff out of 480 had increased LDL and prevalence is $39.59 \%$.

For triglycerides level, 81 doctors out of 220 had increased triglyceride and prevalence in 36.82\%. 194 paramedical staff out of 480 had increased triglycerides and prevalence is $40.42 \%$.

For HDL level, 150 doctors out of 220 had decreased HDL and prevalence was $68.18 \% .280$ paramedical staff out of 480 had decreased HDL levels and prevalence was $58.33 \%$.

For total cholesterol level, age group of $\leq 40,40-60$ and $>60$, prevalence of increased total cholesterol was $35.00 \%$, $22.07 \%$ and $35.00 \%$ respectively among all (Doctor + Paramedical Staff). For HDL levels, in the age group of $\leq 40$, 40-60 and $>60$, prevalence of decreased HDL cholesterol was $67.50 \%, 61.53 \%$ and $56.66 \%$ respectively.

For triglycerides levels in the age group of $<40,40-60$ and $>60$, prevalence of increased triglyceride in $31.87,43.08 \%$ and $43.34 \%$ respectively.

For LDL levels, in the age group of $<40,40-60$ and $>60$, prevalence of increased LDL cholesterol is $31.57 \%, 43.08 \%$ and $44.17 \%$ respectively.

\begin{tabular}{|c|c|c|c|c|c|c|c|c|c|c|c|c|c|c|c|c|}
\hline \multirow[t]{3}{*}{ Profession } & \multicolumn{4}{|c|}{$\begin{array}{c}\text { Total Cholesterol } \\
\text { (mg/d) }\end{array}$} & \multicolumn{4}{|c|}{$\begin{array}{l}\text { HHL Cholesterol } \\
\text { (mg/dl) }\end{array}$} & \multicolumn{4}{|c|}{$\begin{array}{l}\text { LDL Cholesterol } \\
\text { (mg/dl) }\end{array}$} & \multicolumn{4}{|c|}{$\begin{array}{c}\text { Triglyceride } \\
\text { (mg/dl) }\end{array}$} \\
\hline & \multicolumn{2}{|c|}{$<200$} & \multicolumn{2}{|c|}{$\geq 200$} & \multicolumn{2}{|c|}{$<40$} & \multicolumn{2}{|c|}{$\geq 40$} & \multicolumn{2}{|c|}{$<100$} & \multicolumn{2}{|c|}{$\geq 100$} & \multicolumn{2}{|c|}{$\leq 150$} & \multicolumn{2}{|c|}{$>150$} \\
\hline & No & $\%$ & No & $\%$ & No & $\%$ & No & $\%$ & No & $\%$ & No & $\%$ & No & $\%$ & No & $\%$ \\
\hline Doctor $(n=220)$ & 130 & 59.09 & 90 & 40.90 & 150 & 68.18 & 70 & 31.82 & 148 & 67.27 & 72 & 32.73 & 139 & 63.18 & 81 & 36.82 \\
\hline $\begin{array}{l}\text { Paramedical staff } \\
(\mathrm{n}=480)\end{array}$ & 290 & 60.41 & 190 & 39.58 & 280 & 58.33 & 200 & 41.67 & 290 & 60.41 & 190 & 39.59 & 286 & 59.58 & 194 & 40.42 \\
\hline
\end{tabular}

\begin{tabular}{|c|c|c|c|c|c|c|c|c|c|c|c|c|c|c|c|c|}
\hline \multirow[t]{3}{*}{ Profession } & \multicolumn{4}{|c|}{ Total Cholesterol (mg/dl) } & \multicolumn{4}{|c|}{$\begin{array}{l}\text { HHL Cholesterol } \\
\text { (mg/dl) }\end{array}$} & \multicolumn{4}{|c|}{ LDL Cholesterol (mg/dl) } & \multicolumn{4}{|c|}{$\begin{array}{l}\text { Triglyceride } \\
\text { (mg/dl) }\end{array}$} \\
\hline & \multicolumn{2}{|c|}{$<200$} & \multicolumn{2}{|c|}{$\geq 200$} & \multicolumn{2}{|c|}{$<40$} & \multicolumn{2}{|c|}{$\geq 40$} & \multicolumn{2}{|c|}{$\leq 100$} & \multicolumn{2}{|c|}{$>100$} & \multicolumn{2}{|c|}{$\leq 150$} & \multirow[b]{2}{*}{ No } & \multirow[b]{2}{*}{$\%$} \\
\hline & No & $\%$ & No & $\%$ & No & $\%$ & No & $\%$ & No & $\%$ & No & $\%$ & No & $\%$ & & \\
\hline $\begin{array}{c}<40 \\
(\mathrm{~N}=320)\end{array}$ & 208 & 65.00 & 112 & 35.00 & 216 & 67.50 & 104 & 32.50 & 219 & 68.43 & 101 & 31.57 & 218 & 68.125 & 102 & 31.87 \\
\hline $40-60(\mathrm{~N}=260)$ & 201 & 77.30 & 59 & 22.7 & 160 & 61.53 & 100 & 38.46 & 148 & 56.92 & 112 & 43.08 & 148 & 56.92 & 112 & 43.08 \\
\hline$>60(\mathrm{~N}=120)$ & 78 & 65.00 & 42 & 35 & 68 & 56.66 & 52 & 43.34 & 67 & 55.83 & 53 & 44.17 & 68 & 56.66 & 52 & $43 . .34$ \\
\hline
\end{tabular}

\section{DISCUSSION}

The aim of the present study was to focus on the prevalence of dyslipidaemia in medical professionals. In our study, overall prevalence of dyslipidaemia i.e., decrease HDL and increase total cholesterol was more common in doctors versus paramedical staff; females versus males and increased with age. The prevalence of dyslipidaemia was much more than in general population. Effect of differences in life-style and behaviour such as physical inactivity, job stress, work load, altered sleep pattern, alcoholic consumption etc. are the major determining factors. 
Triglyceride value was deranged in $36.82 \%$ in doctors and $40.42 \%$ among paramedical staff. That favours the other general population studies in our country. Triglyceride and HDL are the most common deranged lipids in our country, also known as Indian pattern of Dyslipidaemia. Karnodi et al. 10 found high triglyceride levels in $28.4 \%$. Garrido et al. ${ }^{11}$ also found less derangement in triglycerides in comparison to our study. This can be explained by characteristic Indian pattern of dyslipidaemia.

The prevalence of abnormal HDL profile required for dyslipidaemia diagnosis was deranged in $68.18 \%$ in doctors and $58.33 \%$ among paramedical staff. Konradi et al. 10 low high-density lipoprotein cholesterol (HDL-C) levels in $23.9 \%$ while Garrido et al. ${ }^{11}$ found deranged lipid profile in $80 \%$ of cases, that is very high than in our study and Konradi et al study.

It has been observed that in comparison to western population a relatively lower level of cholesterol appears to predispose Indians to coronary artery disease. ${ }^{12}$ Also, in a Chennai based hospital study, it was shown that around 75\% of patients with myocardial infarction had TC levels $<200$ $\mathrm{mg} / \mathrm{dl}$ indicating that the threshold for the TC levels above which it poses a risk for coronary artery disease is low in Indians. ${ }^{13}$ The contributing factor for hypertriglyceridaemia in our population could be our diet rich in carbohydrates. ${ }^{14}$ high TG levels have been associated with increased levels of small dense LDL which are considered to be highly atherogenic. ${ }^{15}$ Enas etal. found that only 4\%-5\% Indians have optimal HDL level. ${ }^{16}$ Low HDL-C levels are stronger predictor of occurrence and reoccurrence of MI and stroke and are also associated with premature and severe CAD. Oxidative modification of LDL-C is a key process of atherosclerosis and elevated LDL-C has been recognized as a primary risk factor for CAD by NCEP-ATPIII. ${ }^{17}$

There were several limitations to our study. The sample size in our study should have been large. In the coming future, a large prospective study is required to describe the medical occupation benefits versus hazards on individual's personal and social life. There is an emerging need to modify the lifestyle, behaviour and personal habits to save the health of medical professionals. Medical professionals are in sustained exposure to stress in their daily life; it indirectly affects the whole humanity. The present decreased manpower in medical profession compared to general population, long term stressful study pattern without any fruitful or bright future in comparison to other sectors, irrelevant responsibilities offered to a doctor other than to treat the patients etc. my be responsible for this epidemic in our medical community.

\section{CONCLUSION}

Our study has shown that increased job stress and other factors, among doctors and staff decrease HDL and increase total cholesterol. Females are more dyslipidemic compared to males and dyslipidaemia increased with age. The prevalence of dyslipidaemia was much more than the general population. Effect of differences in life and behaviours such as physical inactivity, job stress, work load, altered sleep pattern, more alcoholic consumption etc. in the general population are the major determining factors.

\section{REFERENCES}

[1] Barenson GS, Srinivasan SR, Bao W, et al. Association between multiple cardiovascular risk factors and atherosclerosis in children and young adults. The Bogalusa Heart Study. N Eng J Med 1998;338(23):1650-6.

[2] Fuster V, Kelly BB. Promoting cardiovascular heath in the developing world: a critical challenge to Achieve Global Health. Washington (DC): National Academies Press 2010.

[3] Sample Registration System Million Death Study: Preliminary Report on Causes of Death in India 20112003. New Delhi: Registrar General of India, 2007.

[4] Enas EA, Yusuf S, Mehta JL. Prevalence of coronary artery disease in Asian Indians. Am J Cardiol 1992;70(9):945-9.

[5] Omran AR. The epidemiologic transition. A theory of the epidemiology of population change. Milbank Mem Fund Q 1971;49(4):509-38.

[6] Grundy SM. Small LDL, atherogenic dyslipidaemia and the metabolic syndrome. Circulation 1997;95(1):1-4.

[7] Haffnar SM. Diabetes, hyperlipidemia and coronary artery disease. Am J Cardiol 1999;83(9B):17F-21F.

[8] Craig CL, Marshall Al, Sjostrom M, et al. International physical activity questionnaire: 12-country reliability and validity. Med Sci Sports Exerc 2003;35(8):138195.

[9] Workplace Stress Survey: American Institute of Stress.

[10] Konradi AO, Rotar OP, Korostovtseva LS, et al. Prevalence of metabolic syndrome components in a population of bank employees from St. Petersburg, Russia. Metab Syndr Relat Disord 2011;9(5):337-43. www.libetpub.com

[11] Garrido RA, Semerar MB, Temesgen SM, et al. Metabolic syndrome and obesity among workers at Kanye Seventh Day Adventist Hospital, Botswana. S Afr Med J 2009;99(5):331-4.

[12] American Diabetes Association. Diagnosis and classification of diabetes mellitus. Diabetes care 2006;29 (Suppl 1):S43-S8 http://www.diabetes.org/diabetesprevention/prediabetes.

[13] Kumar S, Roy S. Tropical Heart Disease in India. In: Fanja M, edr. Dyslipidaemia in Indians. Mumbai. Indian College of Physicians 2005: p. 109-18.

[14] Krishnaswami V, Radhakrishna T, John BV, et al. A pattern of ischaemic heart disease: a clinical study. J Indian Med Assoc 1970;55:153-7.

[15] Enas EA, Senthilkumar A, Chennikkara H, et al. Prudent diet and preventive nutrition from pediatrics to geriatrics: current knowledge and practical recommendation. India Heart J 2003;55(4):310-38.

[16] Mora S, Szklo M, Otvos JD, et al. LDL particle subclasses, LDL particle size and carotid atherosclerosis in the Multi-Ethnic study of Atherosclerosis (MESA). Atherosclerosis 2007;192(1):211-7.

[17] Gaziano JM, Hennekens CH, O’Donnell CJ, et al. Fasting triglycerides, high-density lipoprotein and risk of myocardial infarction. Circulation 1997;96(8):2520-5. 